\title{
Culturally Congruent Care: An Omani Reflection
}

\author{
Suad Al Junaibi* \\ Oman College of Health Sciences, Oman
}

*Corresponding author: Suad Al Junaibi, Curriculum \& Teaching Methods Head Adult Health Nursing Department, Head Nursing Program-Muscat Oman College of Health Sciences Muscat, Sultanate of Oman.

Received Date: March 13, 2019

Published Date: March 29, 2019

\section{Mini Review}

Culturally congruent care is possible if cultural values, expressions, or patterns are recognized and appropriately utilized while providing care [1]. Therefore, a culturally competent nursing education should include culturally diverse nursing educators that reflect the communities served, encourage students and educators to speak the service users' language(s), and contend on the cultural values and traditions of the served communities (Anderson et al., 2003). Numerous authors [1-4] Purnell \& Paulanka, 2003) argue that concepts such as cultural awareness, cultural sensitivity, and cultural competence are essential in nursing education. They perceive these concepts as related to important nursing concepts such as health, illness, and care, which signify different things to diverse cultures or people. Thus, familiarity of cultural traditions would allow the healthcare providers to deliver better care and avoid misunderstandings between themselves and other healthcare providers, patients, and their families.

All the Gulf Cooperative Council (GCC) countries adapted nationalization policies encouraged by the vision that local indigenous nurses are more appropriate or suitable for providing nursing care for their local population (Alamri et al., 2006). Local nurses are perceived to provide better patient care because they understand the culture and language of the local people. A study by Mebrouk (2008), which was conducted in Saudi Arabia, highlighted the positive impact of using the Arabic language for communication between service users and local nurses in increasing the satisfaction of service users and their families as well as improving the outcome of nursing care. Another study, conducted by [5] in Saudi Arabia, found that conflict arose between nurses, patients, and families when nurses were not able to communicate in Arabic. Language problems between the nurses and patients may result in miscommunication that could negatively influence their relationship [6]. This failure to communicate with the healthcare providers not only creates a hurdle to accessing healthcare but also challenges trust in the quality of healthcare provided [7-8]. Hence, as language is vital to how a culture operates, a nurse's ability to speak a few words or phrases of the patient's language may reduce communication barriers by encouraging trust [9]. According to Mebrouk (2008), culturally sensitive care based on the service users and their family values is fundamental to the facilitation of effective nursing services.

Omanization of nursing education and practice supports the view that a culturally congruent education would allow the nurses to provide the best care in a holistic, culturally based manner. Authors such as [2] Giger and Davidhizar (2004) [1-3] and Purnell and Paulanka (2003) indicate that culturally congruent nursing education would prepare nurses to provide patients with care that is familiar, supportive, and meaningful in their cultural context. Nevertheless, the Omanization of nursing education may make nursing too parochial and inward-looking by excluding international nursing staff. However, the current $\mathrm{MoH}$ approach to implementing the Omanization policy was not effective in reducing the service users' communication difficulties with the healthcare providers. Most of the service users and their families were Omanis who mainly speak Arabic, and most healthcare providers, including Omani nurses, converse in English. Furthermore, Omani patients who speak other commonly used local languages such as Swahili and Baluchi were not accommodated. The current $\mathrm{MoH}$ nursing program does not offer nursing graduates the cultural or linguistic competence that is necessary for communicating with local service users, which indicated the inability of the $\mathrm{MoH}$ as a healthcare organization to respond effectively to the needs of the public. Gerrish (2000) indicated that high-quality care cannot be attained without effective communication between patients and their healthcare providers; therefore, to improve communication competency, nursing education should embrace the Arabic language and other languages spoken by Omanis. In addition, the nursing education/ curriculum should include content regarding understanding the social and cultural context of the served community to enhance the graduates' awareness of cultural and traditional needs. Hence, to achieve culturally congruent nursing care, the MoH's approaches to nursing education need to encourage the students to use their native language/languages while providing care to facilitate 
understanding of the cultural and linguistic needs of the target populations.

This is in line with other studies that suggest culturally competent nursing education will improve the quality of nursing services, as provision of culturally competent services has the potential to improve healthcare outcomes, increase the efficiency of staff, and result in greater service user satisfaction with services (Anderson et al., 2003; Brach \& Fraser, 2000; Leininger, 1995a). In conclusion, there is evidence from the literature that a culturally competent education would help the students provide efficient care using cultural assessment, which is essential for planning and implementing care [10]; Giger \& Davidhizar, 2008; [11] Purnell \& Paulanka, 2008; Spector, 2009). Thus, creating a nursing program that provides culturally congruent care requires continuous learning based on theory and empirical evidence [12-13].

\section{Acknowledgement}

None.

\section{Conflicts of interest}

No conflict of interest.

\section{References}

1. Leininger M (1991) Culture Care Diversity \& Universality: A Theory of Nursing. National League for Nursing Press, New York, USA.

2. Campinha Bacote J (1999) A model and instrument for addressing cultural competence in health care. J Nurs Educ 38(5): 204-207.
3. Papadopoulos I (2006) Transcultural Health and Social Care: Development of Culturally Competent Practitioners. Churchill Livingstone Elsevier. Edinburgh, Scotland.

4. Papadopoulos I, Tilki M, Taylor G (1998). Transcultural care: A guide for health care professionals. Dinton, Wiltshire (Edts.), Quay Books, England.

5. Aldossary A, While A, Barriball L (2008) Health care and nursing in Saudi Arabia. Int Nurs Rev 55(1): 125-128.

6. Halligan P (2006) Caring for patients of Islamic denomination: Critical care nurses' experiences in Saudi Arabia. J Clin Nurs 15(12): 1565-1573.

7. Weinick R, Krauss N (2000) Racial and ethnic differences in children's access to care. Am J Public Health 90(11): 1771-1774.

8. Woloshin S, Bickell, N, Shwartz L, Gany F, Welch G (1995) Language barriers in medicine in the United States. JAMA 273(9): 724-728.

9. Green Hernandez, C Quinn, Agatha A, Denman Vitale, Susan et al. (2004) Making nursing care culturally competent. Holistic Nursing Practice 18(4): 215-218.

10. Campinha Bacote J (2005) A Biblically Based Model of Cultural Competence in the Delivery of Healthcare Services. Cincinnati, OH: Transcultural C.A.R.E. Associates.

11. Leininger M (2002) Culture care theory: a major contribution to advance transcultural nursing knowledge and practices. Journal of Transcultural Nursing 13(3): 189-192.

12. Jeffreys M (2006) Teaching cultural competence in nursing and health care. Springer Publishing Company, Inc, New York, USA.

13. Leininger M (2002b) Culture care assessments for congruent competency practice. In: M Leininger, M McFarland (Edts.), Transcultural nursing: Concepts, theories, research, and practice $3^{\text {rd }}$ (edn).), McGrawHill Companies, New York, USA, pp: 117-143. 